\title{
Light-dependent changes in the glutathione content of Norway spruce (Picea abies (L.) Karst.)
}

\author{
R. Schupp and H. Rennenberg
}

Fraunhofer Institut für Atmosphärische Umweltforschung, Kreuzeckbahnstr. 19, D-8100 GarmischPartenkirchen, F.R.G.

\section{Introduction}

The tripeptide glutathione is the most abundant low molecular weight thiol in higher plants (Rennenberg, 1982). Its concentration on a cellular basis varies from 0.1 to $0.7 \mathrm{mM}$ depending upon the plant species analyzed (Rennenberg, 1982). Within a plant, the concentration of glutathione is modified by developmental and environmental factors. In spruce needles, the glutathione content undergoes seasonal changes with high concentrations in winter and early spring and low concentrations during the summer (Esterbauer and Grill, 1978). Decreasing concentrations of reduced glutathione are necessary to complete somatic embryo development in wild carrot suspension cultures (Earnshaw and Johnson, 1987). When sulfur is present in excess, the glutathione pool(s) of leaf cells can transiently be expanded (de Kok et al., 1981; Rennenberg, 1984). In the presence of oxidants, like sulfur dioxide or ozone in the atmosphere, the pool(s) of glutathione in leaf cells may be depleted (Wise and Naylor, 1987).

One of the functions of glutathione in plants is its participation in the detoxification of harmful oxygen species (Halliwell,
1984) in the chloroplast. Glutathione acts in this organelle as an intermediate in the pathway of removal of superoxide radicals generated, for example, at light saturation of photosynthesis. As this function of glutathione is predominantly required at high light intensities, it may be assumed that the glutathione content of leaf cells is likely to undergo diurnal changes. The present investigation with needles from spruce trees growing in the field was undertaken to test this assumption.

\section{Materials and Methods}

\section{Plant material}

Experiments were performed with a group of 3 isolated spruce trees about 100-150 yr old, which showed no symptoms of injury. The trees are located on the western slope of a mountain (Katzenstein at Garmisch-Partenkirchen) approximately $765 \mathrm{~m}$ above sea level. Only last year's needles (developed during 1986) were sampled from branches on the western side of the trees, approx. 1.5-2.0 $\mathrm{m}$ above the ground.

\section{Harvest and extraction}

The branches were cut and immediately frozen in liquid nitrogen. Needles were removed from 
the stems and a portion of 3-4 $\mathrm{g}$ fwt was ground to a powder under liquid nitrogen in a mortar. The needle powder was extracted with $0.1 \mathrm{~N}$ hydrochloric acid and $10 \%(\mathrm{w} / \mathrm{v})$ insoluble PVP; the suspension was homogenized and centrifuged (Schupp and Rennenberg, 1988). Hydrochloric acid was used for the extraction of thiols, since it allows the highest recovery of glutathione in spruce $(93 \pm 17 \%)$. For the determination of the recovery within each individual sample, a solution containing GSH, cysteine and $\gamma$-glutamyl-cysteine was added as internal standards to replicates.

\section{Analytical methods}

As previously described (Schupp and Rennenberg, 1988), thiols were separated and quantified by HPLC, after reduction and derivatization with monobromobimane. Aliquots of the supernatants and standard solutions were neutralized with $200 \mathrm{mM}$ CHES (2-(cyclohexylamino)ethane-2-sulfonic acid), $\mathrm{pH} 9.3$, and reduced by the addition of $0.1 \mathrm{ml}$ of $3 \mathrm{mM}$ dithiothreitol (DTT) (60 $\mathrm{min}$ at room temperature) or $0.1 \mathrm{ml}$ of $250 \mathrm{mM} \mathrm{NaBH}{ }_{4}\left(5 \mathrm{~min}\right.$ at $\left.4^{\circ} \mathrm{C}\right)$. The derivatization by addition of the monobromobimane solution simultaneously terminated the reduction. The thiol derivatives of the samples were separated by reverse-phase HPLC on an RP-18 column and fluorimetrically detected at $480 \mathrm{~nm}$ by excitation at $380 \mathrm{~nm}$. The eluting solvent was aqueous $0.25 \%$ acetic acid $(\mathrm{pH} 3.9)$ containing a gradient of $10-14 \%$ methanol (Newtori et al., 1981).

PAR was measured with a quantum meter (Li-185B; quantum sensor Li-190SB; Li-Cor Inc., Lincoln, NE, U.S.A.). Temperature was monitored continuously with a general purpose temperature probe (AC 2626, Analog Devices, Norwood, U.S.A.)

\section{Results}

The glutathione concentration in spruce needles increased during the morning, reaching its maximum level at about 14:00 $h$. It decreased later during the afternoon and remained relatively constant at its minimum level throughout the night (Fig. 1). This diurnal pattern was observed regardless of whether DTT or $\mathrm{NaBH}_{4}$ was used as the reductant in the determination of glutathione (Fig. 1A and B). Maximum glutathione concentrations did not occur at highest temperatures, but at highest light intensities (data not shown). These findings suggest that the glutathione concentration of spruce needles undergoes a light-dependent, diurnal fluctuation. To test this assumption, the glutathione content was determined in needles of branches covered with a black cotton bag. Light intensities of up to $20 \mu \mathrm{E}\left(\mathrm{m}^{2} \cdot \mathrm{s}\right)^{-1}$ and $1-2^{\circ} \mathrm{C}$ higher temperatures were measured inside the bag. When branches were enclosed in the bag at 8:00 h, the glutathione coricentration of the spruce needles did not increase during the day but remained constant at its minimum level (Fig. 1A). Enclosing branches in the bag within the period of increasing glutathione concentrations resulted in an immediate decrease in the glutathione content of the needles; when the bag was removed, the glutathione concentration increased to the level observed in uncovered controls (Fig. 1). This increase was found at light intensities as low as 100 $\mu \mathrm{E}\left(\mathrm{m}^{2} \cdot \mathrm{s}\right)^{-1}$. From this observation and the light intensity measured inside the cotton bag, it can be concluded that a minimum light intensity between 20 and $100 \mu \mathrm{E}$ $\left(\mathrm{m}^{2} \cdot \mathrm{s}\right)^{-1}$ is necessary to mediate the lightdependent increase in the glutathione concentration of spruce needles.

As previously reported by other authors (Esterbauer and Grill, 1978) the glutathione concentration in the needles declined during spring and summer. The diurnal variation of the glutathione content was found to be independent of these seasonal changes (last column, Table l). Its amplitude of approx. $0.2 \mathrm{mM}$ remained constant between March and September (Table I). Apparently, a diurnal rhythm in the glutathione concentration of spruce needles is superimposed on the seasonal changes. This result is surprising, since 


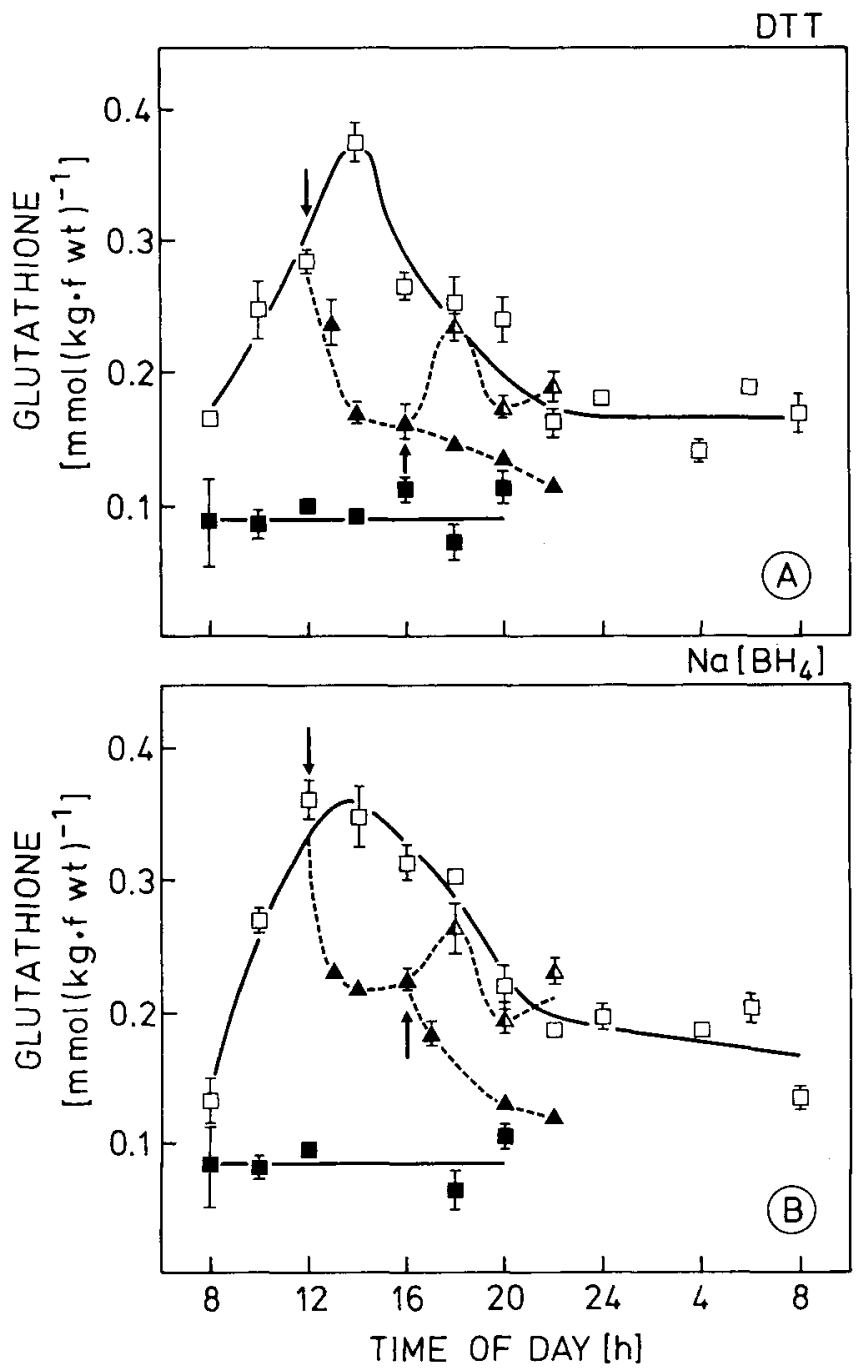

Fig. 1. Diurnal changes in the total glutathione content (GSH + GSSG) of spruce needles. Needles from spruce trees growing in the field were collected at the times of the day indicated beginning at 8:00 $\mathrm{h}$, immediately frozen in liquid nitrogen and homogenized in a mortar. Glutathione and other thiols were extracted from the powder with $\mathrm{HCl}$, reduced with DTT (A) or $\mathrm{NaBH}_{4}(\mathbf{B})$ and derivatized with monobromobimane. The thiol derivatives were quantified by reverse-phase HPLC (Schupp and Rennenberg, 1988). Glutathione was measured in uncovered controls $(\square-0)$, in needles of branches enclosed in a black bag at 8:00 $\mathrm{h}(\square)$ and in needles of branches enclosed in black bags at 12:00 $\mathrm{h}(\boldsymbol{\Delta}-\boldsymbol{\Delta})$. In the latter experiment, one bag was removed at 17:00 $\mathrm{h}$ from one of these branches $(\Delta-\Delta)$.

the same diurnal amplitude in the glutathione concentration was measured at maximum day temperatures of +22 and $-4.5^{\circ} \mathrm{C}$ (Table I). The cyst(e)ine and $\gamma$ glutamyl-cysteine concentrations of the spruce needles were consistently one 
Table I. Glutathione concentrations of spruce needles at different seasons.

\begin{tabular}{lllllll}
\hline \multirow{2}{*}{$\begin{array}{l}\text { Harvest } \\
\text { date }\end{array}$} & \multicolumn{2}{l}{ Temperature $\left({ }^{\circ} \mathrm{C}\right)$} & & \multicolumn{2}{l}{ Glutathione (mmol/kg fwt) } & \\
\cline { 2 - 3 } & $\max$ & $\min$ & & $\max$ & $\min$ & $\max -\min$ \\
\hline 5-6 Mar. & -4.5 & -15.7 & & 0.4 .71 & 0.293 & 0.178 \\
14-15 Apr. & 8.3 & -1.8 & & 0.489 & 0.298 & 0.191 \\
11-12 Jun. & 22.2 & 6.6 & & 0.367 & 0.153 & 0.214 \\
7-8 Jul. & 27.2 & 13.5 & & 0.331 & 0.161 & 0.170 \\
3-4 Sept. & 22.3 & 13.5 & & 0.377 & 0.141 & 0.236 \\
\hline
\end{tabular}

order of magnitude lower than the concentration of glutathione. They varied between 25 and $39 \mu \mathrm{M}$ and 2 and $20 \mu \mathrm{M}$, respectively.

\section{Discussion and Conclusions}

Light-dependent changes in the glutathione concentration in green tissue have previously been observed in laboratory experiments with several species. Manetas and Gavalas (1983) found a higher glutathione level in illuminated leaves of Sedum praeaitum and connected this observation with light-induced intracellular transport. Bielawski and Joy (1986) measured a $50 \%$ elevation of the glutathione content in pea plants upon illumination, apparently due to glutathione synthesis in illuminated chloroplasts (Rennenberg, 1982). Recently, a light-dependent increase in the glutathione content was also observed in laboratory experiments with Euglena gracilis; this increase was prevented by cycloheximide suggesting a photoinduced biosynthesis of glutathione in this alga (Skigeoka et al., 1987). On the other hand, the finding that the 5-oxo-prolinase activity in cultured tobacco cells is inhibited by light at quantum flux densities of about $50 \mu \mathrm{E}\left(\mathrm{m}^{2} \cdot \mathrm{s}\right)^{-1}$ (Rennenberg, unpublished results) may be an indication that degradation via the rate-limiting activity of 5-oxo-prolinase (Rennenberg, 1982) is part of the regulatory processes controlling cellular glutathione levels.

In the present experiments, the same diurnal variations were observed when DTT or $\mathrm{NaBH}_{4}$ was used as a the reductant during the extraction of glutathione. $\mathrm{NaBH}_{4}$, but not DTT, is a reductant sufficiently strong to reduce glutathione-mixed disulfides with proteins and other cellular thiol components. Therefore, the finding of diurnal changes when $\mathrm{NaBH}_{4}$ was used as the reductant is evidence that the degradation of mixed disulfides is not a significant factor in the light-dependent increase in the concentration of glutathione.

As cysteine and $\gamma$-glutamyl-cysteine are found in concentrations significantly lower than the concentration of glutathione, it may be thought that metabolic changes in the glutathione content may result in inverse changes in the concentrations of these glutathione precursors/metabolites. In the present experiments, however, iurnal fluctuations of at least the cysteine concentration were not observed. It may therefore be concluded that the diurnal variations in the glutathione content of spruce needles are due to changes in the export of glutathione out of the needles. Such an expor: of glutathione has previously been reported in other plant species, where this peptide was found to be the predominant long-distance transport 
form of reduced sulfur from the leaves to the roots (Rennenberg, 1984). As an alternative to the export of glutathione, rapid degradation of the cysteine generated during glutathione catabolism, e.g., via a cysteine desulfhydrase, may explain the lack of a diurnal variation in the cysteine content. However, this mechanism appears to be unlikely, since it would be an enormous waste of reduced sulfur and energy. Obviously, further experiments are necessary to achieve a better understanding of the processes regulating the glutathione concentration and its diurnal changes in plant cells.

\section{References}

Bielawski W. \& Joy K.W. (1986) Reduced and oxidised glutathione and glutathione-reductase activity in tissues of Pisum sativum. Planta 169, 267-272

de Kok L.J., de Kan P.J.L., Tanczos O.G. \& Kuiper P.J.C. (1981) Sulphate-induced accumulation of glutathione and frost-tolerance of spinach leaf tissue. Physiol. Plant. 53, 435-438

Earnshaw B.A. \& Johnson M.A. (1987) Control of wild carrot somatic embryo development by antioxidants. Plant Physiol. 85, 273-276
Esterbauer H. \& Grill D. (1978) Seasonal variation of glutathione reductase in needles of Picea abies. Plant Physiol. 61, 119-121

Halliwell B. (1984) In: Chloroplast Metabolism: The Structure and Function of Chloroplasts in Green Leaf Cells. Clarendon Press, Oxford, pp. 259

Manetas Y. \& Gavalas N.A. (1983) Reduced glutathione as an effector of phosphoenopyruvate carboxylase of the crassulacean acid metabolism plant Sedum praealtum D.C. Plant Physiol. 71, 187-189

Newton G.L., Dorian R. \& Fahey R.C. (1981) Analysis of biological thiols: derivatisation with monobromobimane and separation by reversephase high-performance liquid chromatography. Anal. Biochem. 114, 383-387

Rennenberg H. (1982) Glutathione metabolism and possible biological roles in higher plants. Phytochemistry 21, 2771-2781

Rennenberg H. (1984) The fate of excess sulfur in higher plants. Annu. Rev. Plant Physiol. 35, 121-153

Schupp R. \& Rennenberg H. (1988) Diurnal changes in the glutathione content of spruce needles (Picea abies L.). Plant Sci. 57, 113-117

Shigeoka S., Onishi T., Nakano Y. \& Kitaoka S. (1987) Photoinduced biosynthesis of glutathione in Euglena gracilis. Agric. Biol. Chem. 51, 2257-2258

Wise R.R. \& Naylor A.W. (1987) Chilling-enhanced photooxidation I and II. Plant Physiol. 83, 272-277 and 278-282 